\title{
Identification of Antigens of Mycobacterium tuberculosis Using Human Monoclonal Antibodies
}

Robert S. Wallis, Susana L. M. Alde, Diane V. Havlir, Manijeh H. Amir-Tahmasseb, Thomas M. Daniel, and Jerrold J. Ellner Department of Medicine, Case Western Reserve University and University Hospitals, Cleveland, Ohio 44106

\begin{abstract}
Pleural tuberculosis constitutes a human model of local protective immunity to mycobacterial infection as the disease is usually self-limited and recurrent pleurisy is rare. To identify potentially protective antigens of Mycobacterium tuberculosis, 37 human pleural fluid $B$ cell clones were established using EBV and their supernatants assayed by ELISA and Western blot for antibody reactivity with $M$. tuberculosis sonicate and culture filtrate. One antibody identified $29,000,31,000$, and 33,000 bands in culture filtrate, and $31,000,33,000$, and 47,000 bands in sonicate; its species reactivity by ELISA was limited to M. tuberculosis. Eight antibodies identified a 31,000 band in culture filtrate and a 68,000 band in $M$. tuberculosis sonicate, suggesting recognition of a secreted antigen. The species crossreactivity of these eight antibodies extended to $M$. avium. Six antibodies identified multiple bands and had crossreactivity that included $M$. avium and $M$. kansasii. There was no reactivity with recombinant $M$. tuberculosis 65,000 antigen. Tuberculous pleurisy may prove useful in the identifcation of potentially protective mycobacterial antigens, particularly those secreted during active infection, and thus accessible to the human immune response.
\end{abstract}

\section{Introduction}

Tuberculosis remains the most common cause of death from an identifiable infectious agent worldwide; this partly is a reflection of the inadequate protection afforded by the only available vaccine, BCG (1-3). A problem also exists in the diagnosis of infection with Myobacterium tuberculosis by skin testing, as the only available tuberculin purified protein derivative is insufficiently sensitive and specific $(4,5)$. These diffculties may reflect downmodulation of the host immune response by mycobacterial constituents; for example, both arabinogalactan and purified protein derivative can induce suppression by monocytes of cellular immune responses in vitro $(6,7)$. Such suppression may explain both the cutaneous skin test anergy exhibited by some patients with active tuberculosis, and the relative lack of efficacy of a whole mycobacterial vaccine. Purified mycobacterial antigens, therefore, could be of particular value for use as skin test reagents and vaccines.

Address correspondence to Dr. Robert S. Wallis, Department of Medicine, University Hospitals, 2074 Abington Road, Cleveland, $\mathrm{OH}$ 44106.

Received for publication 27 October 1987 and in revised form 1 March 1989.

J. Clin. Invest.

(C) The American Society for Clinical Investigation, Inc.

0021-9738/89/07/0214/06 \$2.00

Volume 84, July 1989, 214-219
Specific antimycobacterial MAbs are essential tools in the identification of species-restricted antigens. A workshop sponsored by the World Health Organization summarized the characteristics of 31 such antibodies, all of murine origin (8). The proteins they recognized ranged in mol wt from 12,000 to 80,000 . The genes for several of these proteins have been cloned in Escherichia coli, and study of their potential value as vaccines is underway.

The use of immunized animals in the identification of potential protective vaccines is, however, not without disadvantages. Heating of mycobacteria before immunization causes considerable loss of antigenic reactivity by denaturation (9), and secreted antigens are inadequately represented in preparations of whole or disrupted organisms. Although immunization with heat-killed mycobacteria generated $\mathrm{T}$ lymphocytes capable of transferring delayed type hypersensitivity, inoculation with viable organisms is required to transfer protective immunity (10). Furthermore, no animal model exists that replicates the pattern of initial resolution and late reactivation that is characteristic of human infection. Finally, wide interspecies variation exists in susceptibility to mycobacterial infection; this may reflect differing immunologic repertoires. Fundamental questions can therefore be raised about the use of murine antibodies to identify antigens of significance in human disease.

As an alternative to animal models, we chose human tuberculous pleural fluid as a source of lymphocytes for the establishment of clones of EBV-transformed B cells. These MAbs display three distinct patterns on Western blotting and appear to identify proteins not previously recognized by murine antibodies.

\section{Methods}

Antigens. Mycobacterial strains were obtained from the Trudeau Mycobacterial Culture Collection (TMCC), Saranac Lake, NY. M. tuberculosis (TMCC 102, strain $\mathrm{H}_{37} \mathrm{Rv}$ ), M. kansasii (TMCC 1201, P-1 [Forbes] strain), M. gordonae (TMCC 1324, P-15 strain), $M$. scrofulaceum (TMCC 1316, Gause strain, serotype 43), and $M$. avium-intracellulare (TMCC 1464, serotype 5) were grown in Proskauer-Beck medium. Mycobacteria were obtained by centrifugation and washed once in water; $M$. tuberculosis organisms were irradiated $4 \times 10^{6} \mathrm{rad}$. Sonication was performed using a $150-\mathrm{W}$ ultrasound probe for $30 \mathrm{~min}$ with the sample chilled on ice. Culture filtrates were dialyzed against water using a Spectrapor 2 membrane (Spectrum Medical, Los Angeles, CA), filtered through a $0.45-\mu \mathrm{m}$ filter, and lyophilized. Protein concentrations of the antigens were determined spectrophotometrically using protein assay (Bio-Rad Laboratories, Richmond, CA).

Cell culture. Pleural fluid mononuclear cells were obtained by density sedimentation of tuberculous pleural fluid over Ficoll-Hypaque. EBV was obtained as the supernatant of B95-8, a marmoset EBVtransformed B lymphoblastoid cell line. Pleural fluid mononuclear cells were cultured at a density of $10^{6} / \mathrm{ml}$ in complete medium (RPMI 1640; Whittaker M. A. Bioproducts, Walkersville, MD) with $2 \mathrm{mM}$ 
L-glutamine, $100 \mu \mathrm{g} / \mathrm{ml}$ gentamicin, $15 \mathrm{mM}$ Hepes (Whittaker M. A. Bioproducts), and $0.1 \mu \mathrm{g} / \mathrm{ml}$ heat-inactivated FCS (10\%; Hyclone, Logan, UT) with $30 \%$ B95-8 supernatant and $0.08 \mu \mathrm{g} / \mathrm{ml}$ cyclosporine A (Sandoz, E. Hanover, NJ) in 2-ml wells. Medium was replaced weekly and assayed by ELISA for antibody to $M$. tuberculosis culture filtrate. After $\sim 3$ wk of culture, clusters of transformed cells, representing expansion of single clones, were transferred by pipette to individual microtiter wells. Complete medium without cyclosporine was then replaced as needed.

ELISA. Polyvinylchloride wells were sensitized with filtrates of $M$. tuberculosis, M. kansasii, M. gordonae, M. scrofulaceum, or $M$. avium-intracellulare $(10 \mu \mathrm{g} / \mathrm{ml})$, or immunoaffinity-purified $M$. tuberculosis arabinogalactan, arabinomannan, or antigen $5(2 \mu \mathrm{g} / \mathrm{ml})$. After overnight incubation, nonspecific adsorption of protein was blocked with $0.5 \%$ BSA (Sigma Chemical Co., St. Louis, MO) in PBS for $1 \mathrm{~h}$ at $37^{\circ} \mathrm{C}$. Plates were washed and $0.05 \mathrm{ml}$ of experimental or control supernatant was added. After $6 \mathrm{~h}$ plates were washed and $0.05 \mathrm{ml}$ of goat anti-human polyvalent Ig alkaline phosphatase conjugate (Sigma Chemical Co.) diluted 1:500 in 1\% BSA/PBS was added. After $3 \mathrm{~h}$ plates were washed and $0.05 \mathrm{ml}$ of disodium $p$-nitrophenyl phosphate $(1 \mathrm{mg} / \mathrm{ml})$ in $0.05 \mathrm{M}$ sodium carbonate buffer, $\mathrm{pH} 9.8$, with $0.02 \%$ $\mathrm{MgCl}_{2}$ was added. OD at $405 \mathrm{~nm}$ was determined with an automated reader. In some experiments monospecific anti-human IgG, IgA, and IgM (diluted 1:1,000) were used in place of the polyvalent conjugate.

Radial immunodiffusion. Ig concentration of cell supernatants was estimated using standard techniques (11). $50 \mu \mathrm{l}$ of 50 -fold concentrated samples was added to wells in agarose containing monospecific antiserum for low levels of IgG or IgM (Kallestad Laboratories, Inc., Kalamazoo, MI). Ring diameter was measured after $48 \mathrm{~h}$ incubation at room temperature. Results were compared with those of known standards.

Preparation of recombinant $M$. tuberculosis 65,000 protein. Lambda gt 11 clone SK116 (in E. coli Y 1089), encoding M. tuberculosis 65,000 protein, was a gift of T. Shinnick (Centers for Disease Control, Atlanta, GA). E. coli lysogens were grown in LB medium at $30^{\circ} \mathrm{C}$ until the $\mathrm{OD}_{600}$ was 1.0 and then warmed to $42^{\circ} \mathrm{C}$ for $20 \mathrm{~min}$. After additional culture at $37^{\circ} \mathrm{C}$ the cells were sedimented, resuspended in $100 \mathrm{mM}$ sodium borate, $\mathrm{pH} 8.3$, and $500 \mathrm{mM} \mathrm{NaCl}$, and lysed by repeated freezing and thawing, addition of lysozyme, and brief sonication.

Western blot. $\mathrm{H}_{37} \mathrm{Rv}$ filtrate or sonicate, or $E$. coli lysate was mixed with an equal volume of reducing sample buffer $(25 \% 0.5 \mathrm{M}$ Tris- $\mathrm{HCl}$, pH 6.8, 4\% SDS, $20 \%$ glycerol, $10 \%$ 2-mercaptoethanol) and heated at $100^{\circ} \mathrm{C}$ for $2 \mathrm{~min} .50 \mu \mathrm{g}$ protein was loaded in each lane of a $10 \%$ SDS-polyacrylamide gel (Bio-Rad Laboratories). After electrophoresis proteins were transferred to $0.2-\mu \mathrm{m}$ nitrocellulose paper (Bio-Rad Laboratories). Protein staining of transfers was performed using Aurodye (Janssen Life Sciences Products, Piscataway, NJ). Nonspecific binding was blocked by incubation with RPMI/FCS $20 \%$ for 2 h at $37^{\circ} \mathrm{C}$. MAbs were diluted fivefold in RPMI/FCS $10 \%$ and allowed to react overnight at $4^{\circ} \mathrm{C}$. After extensive washing blots were incubated for $6 \mathrm{~h}$ with alkaline-phosphatase-conjugated anti-human Ig, anti-human IgG, or anti-human IgM (Sigma Chemical Co.) diluted 1:1,000 in 1\% BSA/PBS. Alkaline phosphatase activity was detected using nitroblue tetrazolium and 5-bromo-4-chloro-3-indoyl phosphate in $100 \mathrm{mM}$ Tris, $\mathrm{pH} 9.5,100 \mathrm{mM} \mathrm{NaCl}$, and $5 \mathrm{mM} \mathrm{MgCl}$.

\section{Results}

Establishment of EBV-transformed B cell clones. Pleural fluid mononuclear cells were initially placed in three 2-ml wells of a 24-well tissue culture plate (Costar, Cambridge, MA) at a density of $2 \times 10^{6} /$ well. Supernatant was tested weekly by ELISA for the presence of antibody to $M$. tuberculosis culture filtrate. As shown in Table I, ELISA OD rose during the second week of culture and was strongly positive by week 4 . At that time individual clusters of cells, each representing expansion of a
Table I. ELISA of Supernatants of EBV-transformed Pleural Fluid Mononuclear Cells before Cloning

\begin{tabular}{lcccc}
\hline & \multicolumn{4}{c}{ OD } \\
\cline { 2 - 5 } Well & Week 1 & Week 2 & Week 3 & Week 4 \\
\hline 1 & - & 0.472 & 1.741 & $>2.000$ \\
2 & 0.084 & 0.554 & 1.734 & $>2.000$ \\
3 & 0.035 & 1.069 & $>2.000$ & $>2.000$ \\
\hline
\end{tabular}

Plates were sensitized with $M$. tuberculosis culture filtrate.

single clone, were transferred by micropipette to individual microtiter wells. In this manner, 37 clones of transformed pleural fluid B cells were successfully propagated. Supernatants of these clones were then tested by ELISA for reactivity with $M$. tuberculosis culture filtrate. The frequency distribution of the ODs of the clonal supernatants was bimodal. 18 supernatants yielded ODs on ELISA of 0.050 or less (mean 0.011 ). The remaining 19 clones (ranging in $\mathrm{OD}$ from 0.130 to $>2.000$ ) were selected for further evaluation.

Species distribution. The species crossreactivity of each MAb was tested by ELISA using culture filtrates of $M$. avium, $M$. kansasii, $M$. gordonae, and $M$. scrofulaceum, as well as two affinity-purified $M$. tuberculosis polysaccharides, arabinogalactan and arabinomannan. The results of this experiment are shown in Table II. When diluted fivefold, the reactivity of antibodies 1-6, although of low intensity, was largely limited to $M$. tuberculosis. Those in the middle group reacted well with both $M$. tuberculosis and $M$. avium. Species reactivity of antibodies 15-19 was less restricted, and included $M$. kansasii. There was little reactivity with $M$. gordonae or $M$. scrofulaceum, or with the two polysaccharide antigens.

Table II. Characterization of MAbs

\begin{tabular}{|c|c|c|c|c|c|c|c|c|c|c|}
\hline MAb & Ig & Bands & TUB & AVI & KAN & GOR & SCR & AG & $\mathbf{A M}$ & PBS* \\
\hline PBS & & & 0.002 & -0.009 & 0.103 & -0.044 & -0.062 & 0.004 & -0.0 & -0.009 \\
\hline 1 & $\mathbf{G}$ & - & 0.011 & 0.000 & -0.019 & -0.078 & -0.005 & -0.004 & -0.0 & -0.021 \\
\hline 2 & $\mathbf{G}$ & - & 0.014 & -0.008 & -0.022 & -0.081 & 0.011 & -0.009 & 0.011 & -0.024 \\
\hline 3 & $\mathbf{M}$ & $\mathbf{A}$ & 0.035 & 0.016 & -0.007 & -0.069 & -0.007 & 0.004 & -0.007 & 0.105 \\
\hline 4 & $\mathbf{G}$ & - & 0.049 & 0.006 & -0.008 & -0.087 & -0.004 & -0.006 & -0.004 & 0.003 \\
\hline 5 & $\mathbf{M}$ & B & 0.075 & 0.034 & -0.006 & -0.061 & 0.027 & 0.003 & 0.027 & 0.096 \\
\hline 6 & $\mathbf{G}$ & - & $\underline{0.127}$ & 0.072 & -0.009 & -0.074 & -0.004 & -0.003 & -0.004 & 0.099 \\
\hline 7 & $\mathbf{M}$ & B & $\underline{0.371}$ & $\underline{0.161}$ & 0.030 & -0.020 & 0.027 & 0.012 & 0.027 & 0.004 \\
\hline 8 & $\mathbf{M}$ & B & $\overline{0.385}$ & $\overline{0.144}$ & 0.097 & -0.016 & 0.025 & 0.019 & 0.025 & -0.013 \\
\hline 9 & $\mathbf{M}$ & C & $\overline{0.397}$ & $\overline{0.158}$ & 0.017 & 0.075 & 0.026 & 0.021 & 0.026 & 0.005 \\
\hline 10 & $\mathbf{M}$ & $\mathrm{C}$ & $\overline{0.401}$ & $\underline{0.167}$ & -0.013 & -0.024 & 0.010 & 0.014 & 0.010 & -0.023 \\
\hline 11 & $\mathbf{M}$ & B & 0.717 & $\overline{0.347}$ & 0.080 & 0.014 & 0.028 & 0.024 & 0.028 & 0.004 \\
\hline 12 & $\mathbf{M}$ & B & $\underline{0.785}$ & $\underline{0.453}$ & 0.008 & -0.033 & 0.017 & 0.027 & 0.017 & -0.013 \\
\hline 13 & $\mathbf{M}$ & B & 0.886 & 0.481 & 0.069 & 0.021 & 0.034 & 0.015 & 0.034 & 0.070 \\
\hline 14 & $\mathbf{M}$ & B & $\underline{1.132}$ & $\underline{0.626}$ & 0.057 & -0.005 & 0.034 & 0.029 & 0.034 & 0.045 \\
\hline 15 & $\mathbf{M}$ & $\mathrm{C}$ & $\underline{0.262}$ & $\underline{0.124}$ & $\underline{0.161}$ & 0.026 & 0.099 & 0.085 & 0.099 & -0.00 \\
\hline 16 & $\mathbf{M}$ & $\mathrm{C}$ & $\overline{0.548}$ & $\underline{0.331}$ & $\underline{0.130}$ & $\underline{0.136}$ & 0.078 & $\underline{0.171}$ & 0.078 & 0.003 \\
\hline 17 & $\mathbf{M}$ & C & $\underline{0.946}$ & 0.691 & $\underline{0.183}$ & $\overline{0.025}$ & 0.032 & $\overline{0.033}$ & 0.032 & 0.065 \\
\hline 18 & $\mathbf{M}$ & C & 1.022 & $\underline{0.575}$ & $\underline{0.169}$ & 0.067 & 0.058 & 0.056 & 0.058 & -0.005 \\
\hline 19 & $\mathbf{M}$ & C & $\overline{1.043}$ & $\overline{0.674}$ & $\overline{0.300}$ & 0.092 & 0.088 & 0.053 & 0.088 & 0.129 \\
\hline
\end{tabular}

* ELISA plates were sensitized with culture filtrate $(10 \mu \mathrm{g} / \mathrm{ml})$ of $M$. tuberculosis (TUB), M. avium-intracellulare (AVI), M. kansasii (KAN), M. gordonae (GOR), or $M$. scrofulaceum (SCR), or affinity-purified $M$. tuberculosis arabinogalactan (AG), or arabinomannan (AM) $(2 \mu \mathrm{g} / \mathrm{ml})$. ODs $>0.1$ are underlined. 
Western blot analysis. Satisfactory Western blots of $M$. tuberculosis filtrate could be obtained with 15 of 19 antibodies tested. Three patterns of reactivity were observed. The first, pattern $\mathrm{A}$, was found in antibody 3 alone. It identified bands at $29,000,31,000$, and 33,000 (Fig. 1). The 33,000 band was of greatest intensity. A second pattern, B, found in antibodies 5 , 7,8 , and $10-14$, identified the 31,000 band. A representative blot, of antibody 13, is shown. Finally, antibodies 9 and 15-19 identified multiple bands $80,000-130,000$ in addition to those recognized by the other antibodies.

Western blot analysis of $M$. tuberculosis sonicate differed from that of filtrate. Antibody 3 identified a band at 47,000 as well as those at 31,000 and 33,000; the 29,000 band was not present. Antibodies 13 and 19 identified only a 68,000 band; the dark staining at the end of these two lanes occurs at the dye front. The Western blot findings are summarized in Table III.

Western blotting with recombinant antigens. To determine the relationship of the 68,000 band to that of cloned 65,000 protein, $E$. coli lysates were prepared with native lambda gt 11 phage and clone SK116, encoding $M$. tuberculosis 65,000 antigen. A murine MAb against the 65,000 protein, WTB78-A1, served as a positive control, identifying only a single band at the appropriate molecular weight in the recombinant lysate. None of the human MAbs tested (3, 5, 6, 10, 13, 15, and 18) reacted with recombinant 65,000 protein. There was considerable crossreactivity with beta galactosidase and other $E$. coli proteins, however, a finding that has been noted by other investigators (12).

Ig type. To determine the Ig type, Western blot analysis was repeated with each of the MAbs using specific anti-human IgG or IgM conjugates. Two antibodies ( 1 and 6) reacted only with anti-IgG (not shown). No reactivity was present with antibodies 2 and 4 . The other MAbs were identified only with anti-IgM conjugate.

To clarify the status of antibodies 2 and 4, ELISA was performed using anti-human IgG, IgM, and IgA conjugates (Table IV). In these experiments wells were sensitized with affinity-purified $M$. tuberculosis antigen 5. Antibodies 2 and 4 were reactive only with the anti-IgG conjugate (OD $>0.300$ ). Antibodies 7 and 8 reacted only with IgM. None were reactive with anti-IgA.

Ig concentration. Radial immunodiffusion using anti-IgG or IgM was performed on 50-fold concentrates of five MAbs. Ig concentrations ranged from 3 to $7.5 \mu \mathrm{g} / \mathrm{ml}$ (Table V). ELISA ODs from Table II are shown for comparison. Differ-

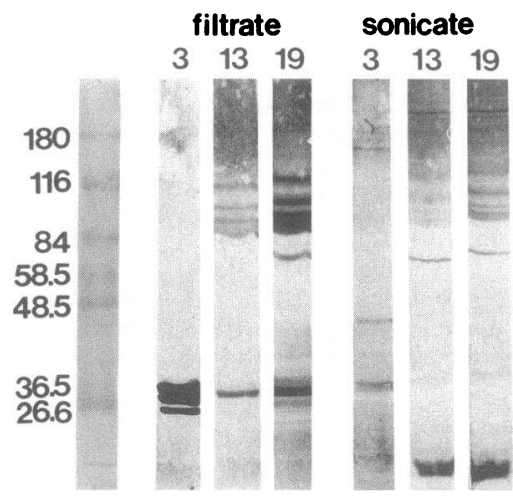

Figure 1. Western blot analysis of $M$. tuberculosis culture filtrate and sonicate using MAbs 3, 13 , and 19.
Table III. Patterns of Western Blot Analysis of M. tuberculosis Filtrate and Sonicate

\begin{tabular}{cccc}
\hline Pattern & Antibody & \multicolumn{1}{c}{ Filtrate } & \multicolumn{1}{c}{ Sonicate } \\
\hline A & 3 & $29,000,31,000,33,000$ & $31,000,33,000,47,000$ \\
B & $5,7,8$, & 31,000 & 68,000 \\
& $10-14$ & & \\
C & $9,15-19$ & $31,000,68,000$ & 68,000 \\
& & and multiple bands $80,000-130,000$
\end{tabular}

ences in OD correlated with Ig isotype, with greater values for IgM than IgG. There was no correlation between antibody level and reactivity by ELISA within Ig isotypes.

Stability. To examine the stability of antibody production over time, supernatants of seven antibodies were collected in 250-ml pools during a 2-mo period. Results of ELISA against $M$. tuberculosis culture filtrate of these samples are shown in Table VI. Four MAbs (7, 9, 13, and 17) exhibited no reduction in ELISA reactivity during this period. ELISA reactivity of antibody 8 was reduced by 50\%. Reactivity of antibodies 1 and 5 declined substantially.

\section{Discussion}

Several observations suggest that pleural tuberculosis constitutes a human model of local protective immunity to mycobacterial infection. First, pleural tuberculosis is usually a selflimited illness. While distant reactivation is common, recurrent pleurisy is rare; even recurrent parenchymal pulmonary disease is as likely to be contralateral or bilateral as ipsilateral (13). Failure to prevent distant relapse is not associated with an inadequate local immune response. Although diminished blastogenesis is present in blood mononuclear cells in up to $30 \%$ of patients with tuberculous pleurisy (often in association with skin test anergy) (14), pleural mononuclear cell responses are preserved. This cell population contains increased numbers of $M$. tuberculosis-reactive CD4+ T lymphocytes as compared with blood (15-18), and increased numbers of the helper-inducer (CD4+ CD45+) T cell subset (19). Pleural fluid cells do not contain the adherent suppressor cells found among circulating cells that may be responsible for systemic immune unresponsiveness (20). These findings suggest that local protective mechanisms are effective in containing the pleural infection despite the inadequacy of the systemic responses, and

Table IV. ELISA of Four MAbs Using Specific Anti-IgG, -IgM, or-IgA Alkaline Phosphatase Conjugates

\begin{tabular}{cccc}
\hline Antibody & IgG & IgM & IgA \\
\hline 2 & $\underline{0.36}$ & 0.01 & 0.01 \\
4 & $\underline{0.34}$ & 0.02 & 0.00 \\
7 & 0.02 & $\underline{0.35}$ & 0.02 \\
8 & 0.01 & $\underline{0.31}$ & 0.00
\end{tabular}

Plates were sensitized with $M$. tuberculosis antigen 5. ODs $>0.1$ are underlined. 
Table V. Ig Concentrations of Five MAbs As Determined by Radial Immunodiffusion

\begin{tabular}{cccc}
\hline \multicolumn{3}{c}{ Ig } & \\
\cline { 1 - 2 } Clone & Type & Concentration & ELISA OD* \\
\hline & & $\mu g / m l$ & \\
1 & IgG & 3.9 & 0.011 \\
2 & IgG & 7.5 & 0.014 \\
4 & IgG & 5.0 & 0.049 \\
7 & IgM & 3.0 & 0.371 \\
8 & IgM & 6.5 & 0.385 \\
\hline
\end{tabular}

* ELISA reactivity with M. tuberculosis culture filtrate (from Table II).

that the antigens identified by this local response might prove to be important in the development of protective vaccines.

We found the B cell population of human tuberculous pleural fluid to contain a high proportion of antigen reactive cells, as $60 \%$ of the transformed B cell clones secreted Ig reactive with culture filtrate of $M$. tuberculosis. This frequency is increased compared with that of $15 \%$ reported by Atlaw et al. in a study of $M$. leprae reactive B cells in the peripheral blood of patients with lepromatous leprosy (21). Antibody production of pleural fluid B cells after EBV transformation was of sufficiently high titer and stability to permit its use in ELISA and Western blotting.

Despite similarities in relative molecular weight, the 68,000 -band identified by many of the human MAbs in $M$. tuberculosis sonicate does not appear to be the same protein as that cloned and sequenced by Young et al. (22) and Shinnick (23). Their 65,000 protein has significant homology to a structural cell wall component of $M$. leprae and to heat shock proteins of many other bacteria (24-27). While the 65,000 protein appears to dominate both humoral and cellular immune responses in animals immunized with heat-killed mycobacteria (28), this does not appear to be true for human subjects, particularly with regard to cellular responses. Although antibodies or T cells recognizing $M$. tuberculosis 65,000 antigen can be detected in the blood of patients with leprosy or tuberculosis (29-31), none of $13 \mathrm{M}$. leprae-reactive human T cell clones, and only 2 of $22 \mathrm{M}$. tuberculosis-reactive human $\mathrm{T}$ cell clones identified recombinant 65,000 antigen of their respective spe-

Table VI. Stability of Antibody Production over a 2-mo Period

\begin{tabular}{cccccccc}
\hline & \multicolumn{8}{c}{ OD } \\
\cline { 2 - 8 } Volume & 1 & 5 & 7 & 8 & 9 & 13 & $17^{*}$ \\
\cline { 2 - 8 } & \multicolumn{8}{c}{ Clone } \\
\hline$m l$ & & & & & & \\
$0-250$ & 0.124 & 0.322 & 0.479 & 0.637 & 0.795 & 0.673 & 0.971 \\
$50-500$ & 0.006 & 0.087 & 0.482 & 0.382 & 0.988 & 0.673 & 0.867 \\
$500-750$ & & 0.039 & & & & &
\end{tabular}

* ELISA plates were sensitized with $M$. tuberculosis culture filtrate. cies $(32,33)$. None of the human MAbs described here recognized the 65,000 antigen.

Antigens at 31,000 and 33,000 were prominent among the bands identified by the human MAbs in M. tuberculosis culture filtrate by Western blot analysis. While the 33,000 band was detected in both antigen preparations, antibodies reactive with the 31,000 band in filtrate detected only a 68,000 band in sonicate. It is possible that this is a secreted antigen, and that the 68,000 band in sonicate represents its precursor. $M$. tuberculosis appears to have secreted antigens that are distinct from structural cell wall or cytoplasmic proteins $(34,35)$. The best studied of these is the 32,000 alpha antigen, the gene for which recently was cloned (36). This antigen contains both crossreacting and species-specific determinants $(37,38)$. The gene for this antigen contains a signal peptide upstream of the sequence for the mature protein that has typical characteristics of a signal peptide. As alpha antigen is both secreted and heat labile, it is not well represented in the killed mycobacteria generally used for immunization in the production of MAbs. The relationship of the 31,000 protein to alpha antigen is under investigation. Secreted antigens of $M$. tuberculosis may be of particular significance in the development of protective immunity, as work by Orme suggests that murine $T$ cells capable of transferring protection to mycobacterial challenge arise only after inoculation with live organisms (10).

11 of the human MAbs recognized multiple bands on Western blot analysis of $M$. tuberculosis culture filtrate. These bands may represent products of partial hydrolysis of single larger proteins, or may reflect the occurrence the same epitope on multiple antigens. Alternatively, the antibodies may not be monoclonal. However, as binding of anti-mycobacterial MAbs to more than one antigen is not uncommon $(8,39)$, this is not a strong argument against monoclonality.

Conventionally, monoclonality is established by sequential limiting dilution cloning. While this technique is well established for the development of $\mathrm{T}$ cell clones and hybridomas, preliminary attempts in this laboratory at limiting dilution cloning of transformed B cells were unsuccessful despite the use of autologous irradiated feeder cells or fibroblast monolayers. The technique of direct transfer of clusters of cells under microscopic visualization proved straightforward, although entirely dependent on operator dexterity. Although no clone secreted more than one Ig type, this is a rather crude measure of monoclonality. This could be more conclusively established either by studies of Ig gene rearrangement (40) or by fusion with a myeloma cell line and subsequent limiting dilution cloning (41).

4 of 19 clones $(21 \%)$ were IgG secreting; the remainder secreted IgM. This is comparable to published reports of EBV transformation of peripheral blood B cells, in which IgM-secreting clones account for $>90 \%$ (42). None of the IgG antibodies could be used satisfactorily for Western blotting.

Reactivity with mycobacterial arabinogalactan and arabinomannan has been described in $\sim 15 \%$ of $M$. tuberculosisreactive murine MAbs, particularly those with broad patterns of reactivity (39). As these polysaccharides are incapable of eliciting a delayed type hypersensitivity response or stimulating $T$ cell blastogenesis in man (43), they are not likely to be useful either in the immunodiagnosis or prophylaxis of tuberculosis. None of the human MAbs were reactive with arabinogalactan or arabinomannan. 
This is the first published report of human $M$. tuberculosis-reactive MAbs. There is considerable interest in identifcation of potentially protective antigens of $M$. tuberculosis given the increasing incidence of tuberculosis worldwide, and the lack of evidence of protection afforded by immunization with BCG. To date, the $M$. tuberculosis DNA library developed by Young et al. has been screened only with murine MAbs. The present human MAbs may prove of value in the identification of recombinant mycobacterial antigens specifically recognized by the human immune response during the course of natural infection. The antigens obtained in this manner are of potential value for diagnosis of tuberculous infection and as vaccines.

\section{References}

1. Medical Research Council. 1972. Bull. WHO. 46:371-385.

2. World Health Organization. 1980. WHO Tech. Rep. Ser. 651: $1-21$.

3. ATS and CDC: BCG vaccines for tuberculosis. 1975. Am. Rev. Respir. Dis. 112:478-480.

4. Nash, D., and J. Douglas. 1980. Anergy in active pulmonary tuberculosis: a comparison between positive and negative reactors and an evaluation of 5 TU and 250 TU skin test doses. Chest. 77:32-37.

5. Edwards, P., and L. Edwards. 1960. Story of the tuberculin test from an epidemiologic viewpoint. Am. Rev. Respir. Dis. 81(Suppl):147.

6. Kleinhenz, M., J. Ellner, P. Spagnuolo, and B. Schacter. 1981. Suppression of lymphocyte responses by tuberculous plasma and mycobacterial arabinogalactan: monocyte dependence and indomethacin reversibility. J. Clin. Invest. 68:153-162.

7. Fujiwara, H., M. Kleinhenz, R. Wallis, and J. Ellner. 1986. Increased interleukin-1 production and monocyte suppressor activity associated with human tuberculosis. Am. Rev. Respir. Dis. 133:73-77.

8. Engers, H., V. Houba, J. Bennedsen, T. Buchanan, S. Chaparas, G. Kadival, O. Closs, J. David, J. van Embden, T. Godal, S. Mustafa, J. Ivanyi, D. Young, S. Kaufmann, A. Khomenko, A. Kolk, M. Kubin, J. Louis, P. Minden, T. Shinnick, L. Trnka, and R. Young. 1986. Results of a World Health Organization-sponsored workshop to characterize antigens recognized by mycobacterium-specific monoclonal antibodies. Infect. Immun. 51:718-720.

9. Seibert, F. 1928. The chemical composition of the active principle of tuberculin. IX. The fractional heat coagulation of the protein of tuberculin. Am. Rev. Tuberc. Pulm. Dis. 17:394-401.

10. Orme, I. 1988. Induction of nonspecific acquired resistance and delayed-type hypersensitivity, but not specific acquired resistance, in mice inoculated with killed mycobacterial vaccines. Infect. Immun. 56:3310-3312.

11. Mancini, G., A. Carbonara, and F. Heremans. 1965. Immunochemical quantitation of antigens by single radial immunodiffusion. Immunochemistry. 2:235-254.

12. Golding, B., G. Inghirami, E. Peters, T. Hoffman, J. Balow, and G. Tsokos. 1987. In vitro generated human monoclonal TNP-specific B cell lines: evidence that human and murine anti-TNP monoclonal antibodies cross-react with $E$. coli beta-galactosidase. J. Immunol. 139:4061-4066.

13. Roper, W., and J. Waring. 1955. Primary serofibrinous pleural effusion in military personnel. Am. Rev. Tuberc. Pulm. Dis. 71:616634.

14. Berger, H., and E. Mejia. 1973. Tuberculous pleurisy. Chest. 63:88-92.

15. Shimokata, K., H. Kawachi, H. Kishimoto, F. Maeda, and Y. Ito. 1982. Local cellular immunity in tuberculous pleurisy. Am. Rev. Respir. Dis. 126:822-824.
16. Rossi, G., B. Balbi, and F. Manca. 1987. Tuberculous pleural effusions: evidence for selective presence of PPD-specific T lymphocytes at the site of inflammation in the early phase of the infection. Am. Rev. Respir. Dis. 136:575-579.

17. Fujiwara, H., and I. Tsuyuguchi. 1986. Frequency of tuberculin-reactive T-lymphocytes in pleural fluid and blood from patients with tuberculous pleurisy. Chest. 89:530-532.

18. Fujiwara, H., Y. Okuda, T. Fukukawa, and I. Tsuyuguchi. 1982. In vitro tuberculin reactivity of lymphocytes from patients with tuberculous pleurisy. Infect. Immun. 35:402-409.

19. Barnes, P., S. Mistry, C. Cooper, C. Pirmez, T. Rea, and R. Modlin. 1989. Compartmentalization of a CD4+ T lymphocyte subpopulation in tuberculous pleuritis. J. Immunol. 142:1114-1119.

20. Ellner, J. 1978. Pleural fluid and peripheral blood lymphocyte function in tuberculosis. Ann. Intern. Med. 89:932-933.

21. Atlaw, T., D. Kozbor, and J. Roder. 1985. Human monoclonal antibodies against Mycobacterium leprae. Infect. Immun. 49:104-1 10.

22. Young, R., B. Bloom, C. Grosskinsky, J. Ivanyi, D. Thomas, and R. Davis. 1985. Dissection of Mycobacterium tuberculosis antigens using recombinant DNA. Proc. Natl. Acad. Sci. USA. 82:25832587.

23. Shinnick, T. 1987. The 65-kilodalton antigen of Mycobacterium tuberculosis. J. Bacteriol. 169:1080-1088.

24. Shinnick, T., M. Vodkin, and J. Williams. 1988. The Mycobacterium tuberculosis 65-kilodalton antigen is a heat shock protein which corresponds to common antigen and to the Escherichia coli GroEL protein. Infect. Immun. 56:446-451.

25. Shinnick, T., D. Sweetser, J. Thole, J. van Embden, and R. Young. 1987. The etiologic agents of leprosy and tuberculosis share an immunoreactive protein antigen with the vaccine strain Mycobacterium bovis BCG. Infect. Immun. 55:1932-1935.

26. Husson, R., and R. Young. 1987. Genes for the major protein antigens of Mycobacterium tuberculosis: the etiologic agents of tuberculosis and leprosy share an immunodominant antigen. Proc. Natl. Acad. Sci. USA. 84:1679-1683.

27. Gillis, T., R. Miller, D. Young, S. Khanolkar, and T. Buchanan. 1985. Immunochemical characterization of a protein associated with Mycobacterium leprae cell wall. Infect. Immun. 49:371377.

28. Kaufmann, S., U. Vath, J. Thole, J. Van Embden, and F. Emmrich. 1987. Enumeration of T cells reactive with Mycobacterium tuberculosis organisms and specific for the recombinant mycobacterial 64-kDa protein. Eur. J. Immunol. 17:351-357.

29. Thole, J., H. Dauwerse, P. Das, D. Groothuis, L. Schouls, and J. van Embden. 1985. Cloning of Mycobacterium bovis BCG DNA and expression of antigens in E. coli. Infect. Immun. 50:800-806.

30. Emmrich, F., J. Thole, J. van Embden, and S. Kaufmann. 1986. A recombinant 64 kilodalton protein of Mycobacterium bovis BCG specifically stimulates human T4 clones reactive to mycobacterial antigens. J. Exp. Med. 163:1024-1029.

31. Thole, J., W. Keulen, J. de Bruyn, A. Kold, D. Groothuis, L. Berwald, R. Tiesjema, and J. van Embden. 1987. Characterization sequence determination and immunogenicity of a 64-kilodalton protein of Mycobacterium bovis BCG expressed in E. coli K-12. Infect. Immun. 55:1466-1475.

32. Mustafa, A., H. Gill, A. Nerland, W. Britton, V. Mehra, B. Bloom, R. Young, and T. Godal. 1986. Human T-cell clones recognize a major Mycobacterium leprae protein antigen expressed in $E$. coli. Nature (Lond.). 319:63-66.

33. Oftung, F., A. Mustafa, R. Husson, R. Young, and T. Godal. 1987. Human $T$ cell clones recognize two abundant Mycobacterium tuberculosis protein antigens expressed in Escherichia coli. J. Immunol. 138:927-931.

34. Yoneda, M., and Y. Fukui. 1965. Isolation, purification and characterization of extracellular antigens of Mycobacterium tuberculosis. Am. Rev. Respir. Dis. 92(Suppl):9-18. 
35. Abou-Zeid, C., I. Smith, J. Grange, T. Ratliff, J. Steele, and G. Rook. 1988. The secreted antigens of Mycobacterium tuberculosis and their relationship to those recognized by the available antibodies. $J$. Gen. Microbiol. 134:531-538.

36. Matsuo, K., Y. Yamaguchi, A. Yamazaki, H. Tasaka, and T. Yamada. 1988. Cloning and expression of the Mycobacterium bovis BCG gene for extracellular alpha antigen. J. Bacteriol. 170:3847-3854.

37. Tasaka, H., K. Kiyotani, and Y. Matsuo. 1983. Purification and antigenic specificity of alpha protein from Mycobacterium tuberculosis and Mycobacterium intracellulare. Hiroshima J. Med. Sci. 32:1-8.

38. Tsukamura, M. 1976. Numerical classification of slowly growing mycobacteria. Int. J. Syst. Bacteriol. 26:409-420.
39. Daniel, T., and G. Olds. 1985. Demonstration of a shared epitope among mycobacterial antigens using a monoclonal antibody. Clin. Exp. Immunol. 60:249-258.

40. Tonegawa, S. 1983. Somatic generation of antibody diversity. Nature (Lond.). 302:575-581.

41. Emanuel, D., J. Gold, J. Colacino, C. Lopez, and U. Hammerling. 1984. A human monoclonal antibody to cytomegalovirus (CMV). J. Immunol. 133:2202-2205.

42. Kozbor, D., A. Lagarde, and J. Roder. 1982. Human hybridomas constructed with antigen-specific Epstein-Barr virus-transformed cell lines. Proc. Natl. Acad. Sci. USA. 79:6651-6655.

43. Yamamura, Y., A. Misaki, and I. Azuma. 1972. Chemical and immunological studies on polysaccharide antigens of mycobacteria, nocardia, and corynebacteria. Bull. Int. Union Tuberc. 47:181-191. 